This item was submitted to Loughborough's Research Repository by the author.

Items in Figshare are protected by copyright, with all rights reserved, unless otherwise indicated.

\title{
Low cost optical fibre based Fabry Pérot strain sensor production
}

PLEASE CITE THE PUBLISHED VERSION

PUBLISHER

(c) Institute of Physics

VERSION

AM (Accepted Manuscript)

LICENCE

CC BY-NC-ND 4.0

REPOSITORY RECORD

Tuck, Christopher, Richard J.M. Hague, and Crispin Doyle. 2019. "Low Cost Optical Fibre Based Fabry Pérot Strain Sensor Production”. figshare. https://hdl.handle.net/2134/5660. 
This item was submitted to Loughborough's Institutional Repository (https://dspace.lboro.ac.uk/) by the author and is made available under the following Creative Commons Licence conditions.

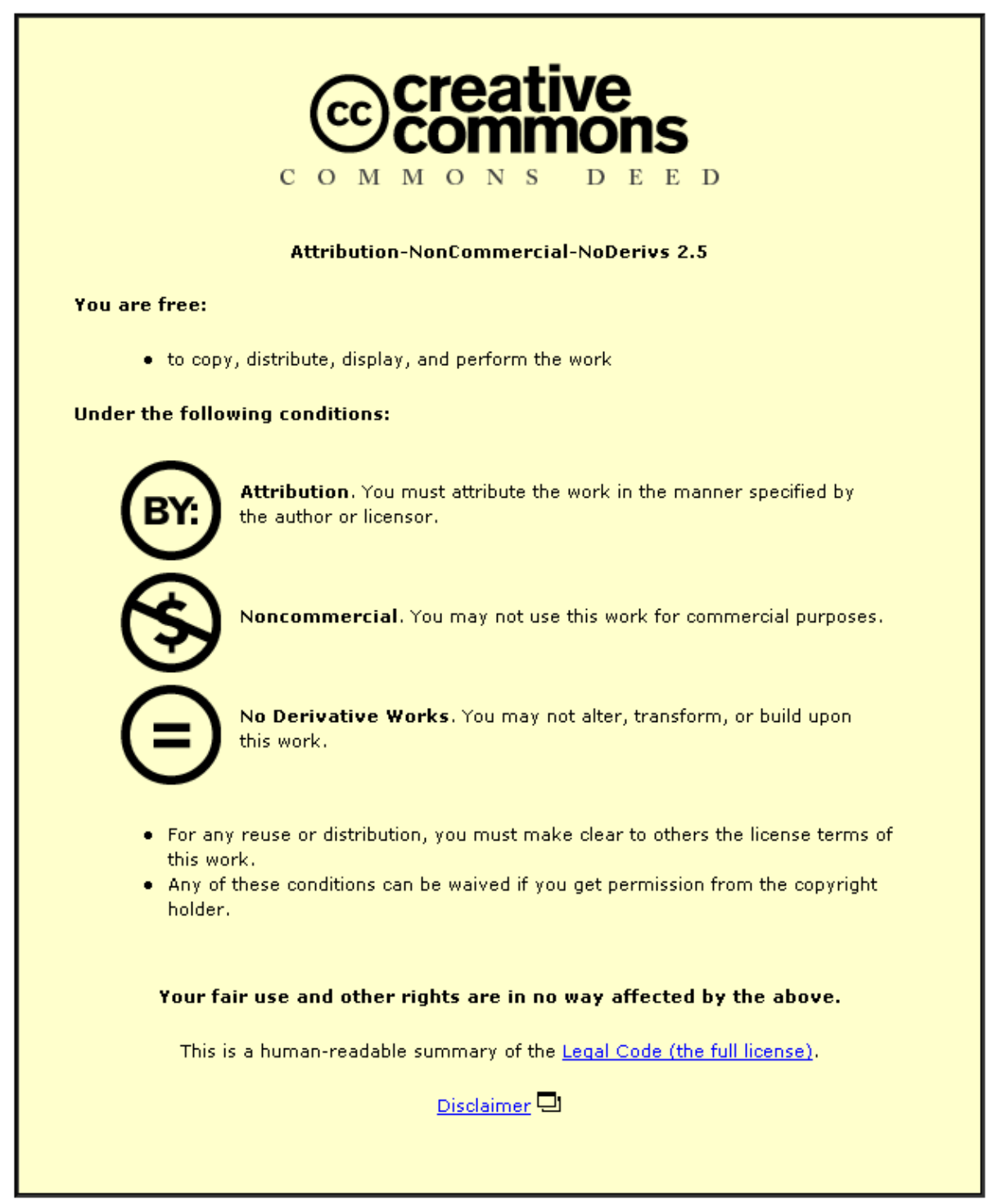

For the full text of this licence, please go to: http://creativecommons.org/licenses/by-nc-nd/2.5/ 


\title{
Low Cost Optical Fibre Based Fabry Pérot Strain Sensor Production
}

Dr Christopher J. Tuck* ${ }^{*}$, Dr Richard Hague ${ }^{1}$ and Dr Crispin Doyle ${ }^{2}$

*Formerly, Sensors and Composites Group, Engineering Systems Department, Defence Academy, Cranfield University, Shrivenham, Oxfordshire, UK.

${ }^{1}$ Rapid Manufacturing Research Group, Wolfson School of Mechanical and Manufacturing Engineering, Loughborough University, Leicestershire, UK.

${ }^{2}$ Smart Fibres Ltd. Centennial Court, Easthampstead Road, Bracknell, Berkshire, UK

\begin{abstract}
The production of Fabry-Pérot based optical fibre sensors has long been an iterative and labour intensive process. This paper demonstrates the production of Fabry-Pérot based optical fibre strain sensors using chemical etching techniques. Utilising hydrofluoric acid (HF) and singlemode optical fibres, a preferential etching mechanism was observed around the core portion of the fibres. These etched fibre ends were then spliced together successfully to form enclosed Fabry-Pérot cavities between 18 and $60 \mu \mathrm{m}$ in length. These sensors have then been deployed for strain monitoring and have been subjected to strains of up to $1400 \mu \varepsilon$ on tensile test specimens. Etched Fabry-Pérot cavity lengths were monitored using a white light interferometry (WLI) system based on a CCD spectrometer and an $850 \mathrm{~nm}$ super luminescent diode (SLD). A linear and repeatable response to these strain tests has been shown with negligible sensitivity to temperature.
\end{abstract}

\section{Introduction}

Sensors are an integral part of modern structures, instruments and processes. The majority of these devices are based on traditional electrical technology, e.g. the foil strain gauge and the thermocouple. However, these sensors are unsuitable for monitoring in some harsh environments. Recently, considerable interest has developed in the deployment of optical fibre sensors (OFS) in harsh environments and, specifically, for structural health monitoring ${ }^{1}$. The use of OFS could lead to structures that are able to monitor their environment and therefore, increased efficiency in design and the development of smart structures is possible. The 
versatility of these sensors means that the monitoring of different measurands such as: strain, temperature, pressure and chemical species analysis ${ }^{2}$ is possible. Optical fibres are conventionally manufactured from fused silica $\left(\mathrm{SiO}_{2}\right)$ substrates and hence, have properties inherent with that material, i.e. immunity to electromagnetic interference, can be used in intrinsically safe environments and are chemically resistant to many industrial processes. The addition of a dopant is necessary in the production of such optical fibres to modify the refractive index and form the core portion of the fibre that is required for waveguiding.

This paper highlights a novel fabrication method that modifies the topography of the core and cladding region of cleaved singlemode optical fibres with Hydrofluoric Acid (HF) in order to produce discrete, strain-sensing $\mathrm{OFS}^{3}$ based on the Fabry-Pérot étalon ${ }^{4}$.

\section{State of the Art}

OFS fit into two classes; discrete sensors (such as those based on Fibre Bragg Gratings $^{5}$ (FBG) and Fabry-Pérot ${ }^{4}$ (FP) devices); and distributed OFS, (for example, those based on Brillouin Scattering ${ }^{6,7}$ or Raman Scattering ${ }^{8}$ ). This paper is concerned with discrete strain sensors based on a Fabry-Pérot device.

FBG type sensors have been popularised in recent years for many applications ${ }^{9}$. However, disadvantages exist in terms of their strain cross-sensitivity, susceptibility to temperature fluctuations and licensing issues ${ }^{10,11}$. FP sensors also have their disadvantages, depending on the type constructed. Two types of FP sensor exist; extrinsic $^{12}$ (EFP) and intrinsic ${ }^{13}$ (IFP) devices. EFP devices are those that allow light to leave a cleaved fibre end, where the light is then modulated and then returns to the same or different fibre. IFP devices contain the light within the sensor where the light is modulated whilst within the fibre. Figure 1 shows a number of EFP and IFP designs under current use or research. 


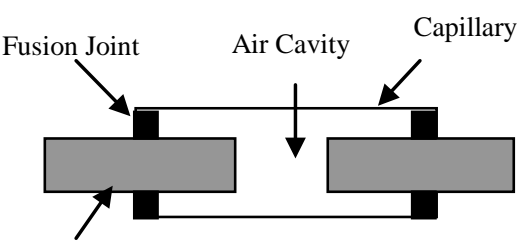

Fibre

(a) extrinsic

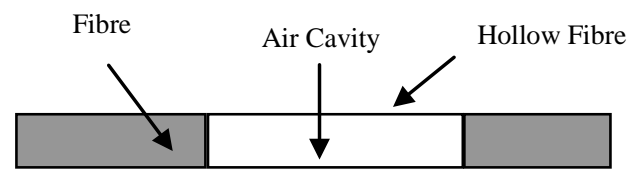

(c) in-line fibre étalon



(b) intrinsic

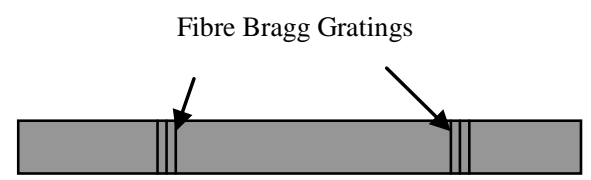

(d) fibre Bragg grating

Figure 1a to d. Schematic illustrations of (a) extrinsic, (b) intrinsic, (c) in line (ILFE) ${ }^{14}$ and (d) FBG based FP $^{15}$ sensor designs.

\subsection{Specific Problems with FP-Based Sensor Construction}

A number of issues are associated with FP based sensor construction. For EFP sensors, optical fibre-ends can be contaminated and threading into a capillary can damage the end-faces. Current manufacturing processes are manual, thus reproducibly setting the air-cavity can also be difficult, meaning that each sensor has to be calibrated prior to use and the gauge length determined after fabrication. Splicing the capillary onto the fibres can result in misalignment of the fibre ends within the capillary. The capillary element of the sensor has, intuitively, to be larger than the fibre used to construct the sensor, i.e. the capillary can have an external diameter of $300 \mu \mathrm{m}$ in comparison to $125 \mu \mathrm{m}$ for the optical fibre. This can lead to problems during embedment for certain applications ${ }^{1}$.

For intrinsic sensors, previous work by Lee et al. ${ }^{16}$ has shown that the addition of coatings to produce stronger reflections from the fibre ends has resulted in lower strength fusion splices when compared to those produced using clean fibre-to-fibre splices ${ }^{17}$. For IFP sensors, the frequently quoted issues with Fibre Bragg gratings apply, namely, sensitivity to axial, radial and lateral strain and temperature ${ }^{18}$. 


\subsection{Chemical Etching}

Chemical etching of fused silica substrates $\left(\mathrm{SiO}_{2}\right)$ has been studied extensively by Monk et al. ${ }^{19}$. Etching has been performed using hydrofluoric acid (HF) and the chemical equation is shown in Equation 1.

$$
\mathrm{SiO}_{2}+6 \mathrm{HF} \rightarrow 2 \mathrm{H}_{3} \mathrm{O}^{+}+\mathrm{SiF}_{6}^{2-}
$$

Equation 1

The addition of a dopant to a $\mathrm{SiO}_{2}$ matrix has been suggested by Monk et al. ${ }^{19}$ to increase the etch rate of doped areas. Murphy et al. ${ }^{20}$ have produced chemical sensors using a technique where the core of the fibre was preferentially etched to form a cavity. The etching profile followed the dopant profile. The etched fibre was used as a “containment cell” for an analyte sensitive “dye”.

Abeysinghe et al. ${ }^{21}$ has etched fibres to produce an optical fibre pressure sensor using Borosilicate multimode fibre with core diameters of 190 and $360 \mu \mathrm{m}$. The ends of these fibres were cleaved and then coated in a photoresist that was illuminated by ultraviolet (UV) light. The photoresist was then developed, removing the portion that had been irradiated and the fibres were etched in a buffered HF solution. A silicon diaphragm was then bonded to the fibre to form an FP cavity. This sensor, although of original construction, ignores some of the advantages of using telecommunications grade fibre, i.e., the etching procedure does not benefit from the dopant-enhanced etching seen in germanium-doped fibres. In addition, the type of fibre used is large, in the smallest case (the $190 \mu \mathrm{m}$ core) the total fibre diameter is $200 \mu \mathrm{m}$ and the largest fibre used was $360 \mu \mathrm{m}$ in diameter. Zhu et al. $^{22}$ have recently reported a similar type of pressure sensor using $125 \mu \mathrm{m}$ fibres and an all silica construction.

This paper describes a method for producing etched fibre-ends that have subsequently been used to form optical fibre sensor devices through fusion splicing. The devices were based on the Fabry-Pérot principle and for this reason existing Fabry-Pérot interrogation schemes were used during manufacture and the monitoring of strain.

\section{Description}

SM800 (Fibercore) optical fibres were chosen for etching as they were suitable for interrogation using the demodulation equipment described later. The characteristics of this fibre type are outlined in Table 1. 


\begin{tabular}{|c|c|c|c|c|c|}
\hline Fibre & Type & $\begin{array}{c}\text { Core } \\
\text { Dopant }\end{array}$ & $\begin{array}{c}\text { Core } \\
\text { Diameter } \\
(\mu \mathrm{m})\end{array}$ & $\begin{array}{c}\text { Cladding } \\
\text { Diameter } \\
(\mu \mathrm{m})\end{array}$ & $\begin{array}{c}\text { Numerical } \\
\text { Aperture } \\
(\mathrm{NA})\end{array}$ \\
\hline SM800 & Singlemode & $\mathrm{GeO}_{2}$ & 5.6 & 125 & 0.13 \\
\hline
\end{tabular}

Table 1. Optical fibres used during etching experiments.

Fibres for conventional etching were prepared by cutting the fibres to length ( 300 $\mathrm{mm}$ ) and removing the protective buffer coating. The fibres were then cleaved in order to produce a flat end-face on the fibre.

All etching was carried out using HF acid (48\%), where fibres were dipped vertically into a quantity of HF acid approximately $5 \mathrm{~mm}$ deep; experiments were carried out at ambient temperatures. Etch times for the fibres were 10, 20 and 30 minutes. After the immersion time, the fibres were removed from the HF acid, washed in deionised water and left to dry in air.

A batch of 8 singlemode SM800 fibres was used to study the effect of agitation on the etch rate of the optical fibres. The HF acid was kept at ambient temperature and the stirring rate, as controlled by a Kivka platform, equivalent to setting 3 was found to be most suitable (not violent stirring but achieving a constant "swirl”). The SM800 fibres were etched for 30 minutes.

\subsubsection{CCD Interrogation}

An interrogation scheme similar to that employed by Liu et al. ${ }^{23}$ was used for interrogating the sensors. It also served as a convenient method of checking the suitability of the etched cavities for use in sensor production. A cleaved fibre connected to the demodulation equipment was placed on one side of a translation stage located on a BIT BFS60CCD fusion splicer. An etched fibre-end was placed on the opposing arm. The etched fibre ends were then aligned with the core of the opposing fibre using the splicer translation stages and any interference fringes recorded by a PC attached to the demodulation equipment. A wavelength vs. intensity plot was generated. The cavity gap of the sensor produced was determined from the fringe pattern developed from the cavity. Equation 2 shows the relationship between the cavity gap and the fringe pattern produced by the sensor. 


$$
d=\frac{m \lambda_{1} \lambda_{2}}{2 n(\Delta \lambda)}
$$

Where, $\lambda_{1}$ and $\lambda_{2}$ are wavelengths of two fringes that are $2 m \pi$ out of phase, $m$ is an integer and $n$ is the refractive index of the cavity.

Etched fibre based Fabry-Pérot devices were produced by fusion splicing. The system was devised to produce a Fabry-Pérot device by splicing two etched cavities together. This methodology allowed continuous monitoring of interference fringes during the procedure and thus a check on whether a working sensor was created. Two etched fibres of the same cladding diameter were selected for splicing; the un-etched portion of a fibre was spliced to the demodulation coupler arm. A spectrum of the output from this single end was taken as a reference. The second etched fibre was then lined up with the spliced fibre. The fibres were cleaned with a gentle arc (5 mA and $0.5 \mathrm{~s}$ ) to remove dirt and dust from the fibres. Close attention was paid to aligning the fibres to produce prominent interference fringes. The two etched fibre ends were then butted together and fused together using an electrical arc of $12 \mathrm{~mA}$ for $0.6 \mathrm{~s}$.

\subsection{Mechanical Testing of Etched sensors}

Etched sensors were attached to $150 \mathrm{~mm}$ x $25 \mathrm{~mm}$ x $1 \mathrm{~mm}$ stainless steel coupon with cyanoacrylate adhesive. The etched cavity was bonded to the coupon where the buffered portion of the fibre began. Care was taken not to get any of the adhesive around the etched portion of the fibre. A foil strain gauge was placed on the coupon to give reference data for strain.

Initial experiments were carried out on a Hounsfield Tensometer with a $2.2 \mathrm{kN}$ load cell. The samples were tested under step loading of $0.5,1,1.5$ and $2.2 \mathrm{kN}$, and then reversed in the same increments to $0 \mathrm{kN}$. The sensor was then loaded directly up to $2.2 \mathrm{kN}$. A steady gap reading from the sensor was achieved by changing the system acquisition speed and averaging the readings acquired. Further strain testing was carried out using a Zwick 1484 machine in order to produce a larger displacement of the etched sensor cavity. The machine had a $200 \mathrm{kN}$ load cell. The loading 
conditions were as follows; the coupon was loaded at $0.5 \mathrm{~mm} \mathrm{~min}^{-1}$ and ramped in the following pattern:

$$
0 \rightarrow 4 \rightarrow 0 \rightarrow 4 \rightarrow 0 \rightarrow 4 \rightarrow 2.5 \rightarrow 4 \rightarrow 0 \mathrm{kN}
$$

The acid etched optical fibre sensors were mounted to the coupon as mentioned previously and a foil strain gauge was again attached.

\section{$4 \quad$ Results and Discussion}

Etching of optical fibres under ambient and non-agitated conditions resulted in preferential etch rates at the core of the SM800 type fibres. Using optical microscopy it was possible to observe the cavity depth and reduction in the cladding diameter from the effects of etching. Figure 2 shows a typical micrograph of the cavity produced from a cleaved SM800 fibre.

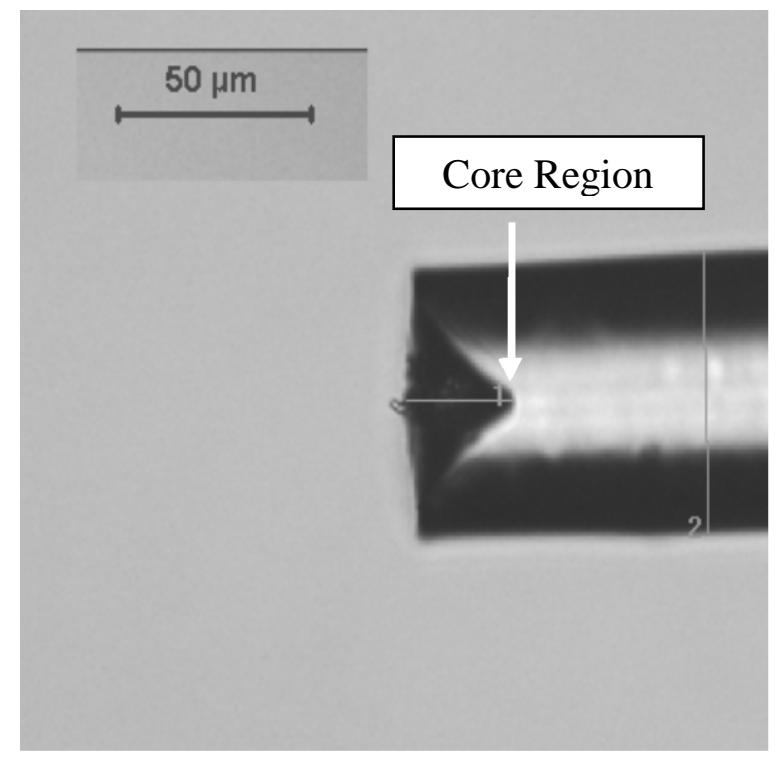

Figure 2. Optical micrograph of SM800 fibre etched for 30 minutes.

From the image presented in Figure 2 a noticeable flatter profile (highlighted with white arrow) at the core region is evidenced, i.e., the taper from the etching process is removed. Indications of the average etch rate measured using optical microscopy are given in Table 2. 


\begin{tabular}{|c|c|c|c|c|c|}
\hline $\begin{array}{l}\text { Fibre } \\
\text { Type }\end{array}$ & $\begin{array}{l}\text { Etch } \\
\text { Time } \\
\text { (min) }\end{array}$ & $\begin{array}{c}\text { Cladding } \\
\text { Radius } \\
\text { ( } \mu \mathrm{m})\end{array}$ & $\begin{array}{c}\text { Cladding } \\
\text { Etch Rate } \\
(\mu \mathrm{m} / \mathrm{min})\end{array}$ & $\begin{array}{c}\text { Etched Core } \\
\text { Depth } \\
(\mu \mathrm{m})\end{array}$ & $\begin{array}{c}\text { Core Etch } \\
\text { Rate } \\
\text { ( } \mu \mathrm{m} / \mathrm{min})\end{array}$ \\
\hline \multirow[t]{3}{*}{ SM800 } & 30 & 33.9 & 1.0 & 23.6 & 1.8 \\
\hline & 20 & 38.9 & 1.2 & 18.5 & 2.2 \\
\hline & 10 & 48.4 & 1.4 & 11.9 & 2.7 \\
\hline
\end{tabular}

Table 2. Etch times and rates for SM800 optical fibre.

Table 2 shows the etch rate for core formation, where a clear reduction in etch rate is noticeable with increasing etch time. This can be explained by the formation of reaction products on the sample surface, as explained by Tso and Pask ${ }^{24}$, who point to the reaction being dependent on diffusion of the acid to the sample surface. These reaction products can be removed through agitation of the liquid during etching. Using SEM it was possible to study the end-faces of the etched fibres in comparison with a cleaved "virgin” optical fibre (Figure 3).



(a)

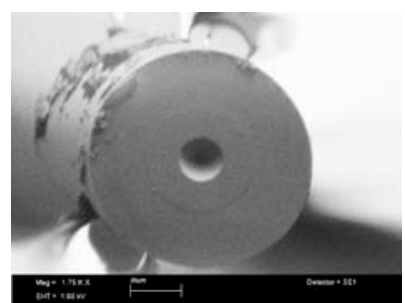

(b)

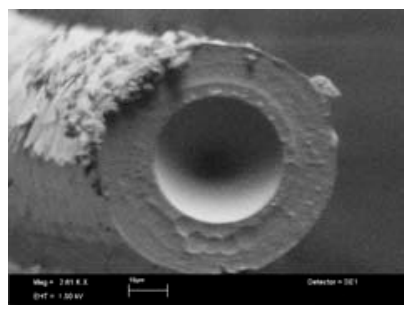

(c)

Figure 3. SEM micrographs of (a) virgin fibre surface, (b) SM800 etched for 10 minutes and (c) SM800 etched for 30 minutes.

Figure 3 shows the end-face of cleaved and etched optical fibres, Figure 3a shows the smooth profile of a recently cleaved fibre end that forms the semi-reflective mirror necessary for the Fabry-Pérot device. No discernable roughness is apparent in either of the core regions of Figure $3 b$ and $c$, though c shows significant roughness in the cladding portion of the fibre.

The increased etch rate for the fibre core from HF acid etching is likely to be due to the presence of the $\mathrm{GeO}_{2}$. As mentioned by Monk et al. ${ }^{19}$, doped glasses tend to etch faster. According to Greenwood and Earnshaw ${ }^{25}$, the chemistry of vitreous $\mathrm{GeO}_{2}$ resembles that of fused silica. The reaction between $\mathrm{HF}$ acid and $\mathrm{GeO}_{2}$ is similar to $\mathrm{SiO}_{2}$ in that the final product is $\mathrm{GeF}_{6}{ }^{2-}$.

$$
\mathrm{GeO}_{2}+6 \mathrm{HF} \rightarrow 2 \mathrm{H}_{3} \mathrm{O}^{+}+\mathrm{GeF}_{6}^{2-}
$$


An important difference in the chemistry is the bond energy of Ge-O cf. Si-O. The Handbook of Physics and Chemistry ${ }^{26}$ gives average bond energies for Ge-O as $662 \mathrm{~kJ} \mathrm{~mol}^{-1}$ and Si-O as $799 \mathrm{~kJ} \mathrm{~mol}^{-1}$. This could mean that $\mathrm{GeO}_{2}$ species in the core region are etched preferentially, being a weaker bond. This could lead to a larger surface area of $\mathrm{SiO}_{2}$ to attack, which has been also been shown to increase etch rate ${ }^{19}$.

Agitation of the etchant has been reported ${ }^{24}$ to increase the etch rate of fused silica substrates. An experiment was carried out in order to study the effect on the etching of fused silica fibre. SM800 fibre was again used. Table 3 shows the etch rate for SM800 fibre etched for 30 minutes.

\begin{tabular}{|l|c|c|c|c|c|}
\hline $\begin{array}{l}\text { Fibre } \\
\text { Type }\end{array}$ & $\begin{array}{c}\text { Etch } \\
\text { Time } \\
(\mathbf{m i n})\end{array}$ & $\begin{array}{c}\text { Core } \\
\text { Depth } \\
(\boldsymbol{\mu m})\end{array}$ & $\begin{array}{c}\text { Cladding } \\
\text { Diameter } \\
(\boldsymbol{\mu m})\end{array}$ & $\begin{array}{c}\text { Core Etch } \\
\text { Rate } \\
\left(\mu \mathbf{m ~ m i n}^{-\mathbf{1}}\right)\end{array}$ & $\begin{array}{c}\text { Cladding } \\
\text { Etch Rate } \\
\left(\boldsymbol{\mu m} \mathbf{m i n}^{-1}\right)\end{array}$ \\
\hline SM800 & 30 & $15 \pm 1$ & $26.4 \pm 0.7$ & $2.16 \pm 0.03$ & $1.7 \pm 0.02$ \\
\hline
\end{tabular}

Table 3. Agitated etching of SM800 fibre for 30 minutes.

Table 3 clearly shows an increase in the etch rate for both the cladding and core of SM800 fibre when compared to the original values for a 30 minute etch in Table 2. The etch rate is closer to that shown for a 10 minute etch. This leads to the conclusion that the products from etching inhibit the reaction rate, as studied by Tso and Pask ${ }^{24}$. Micrographs of the agitated fibre are shown in Figure 4.
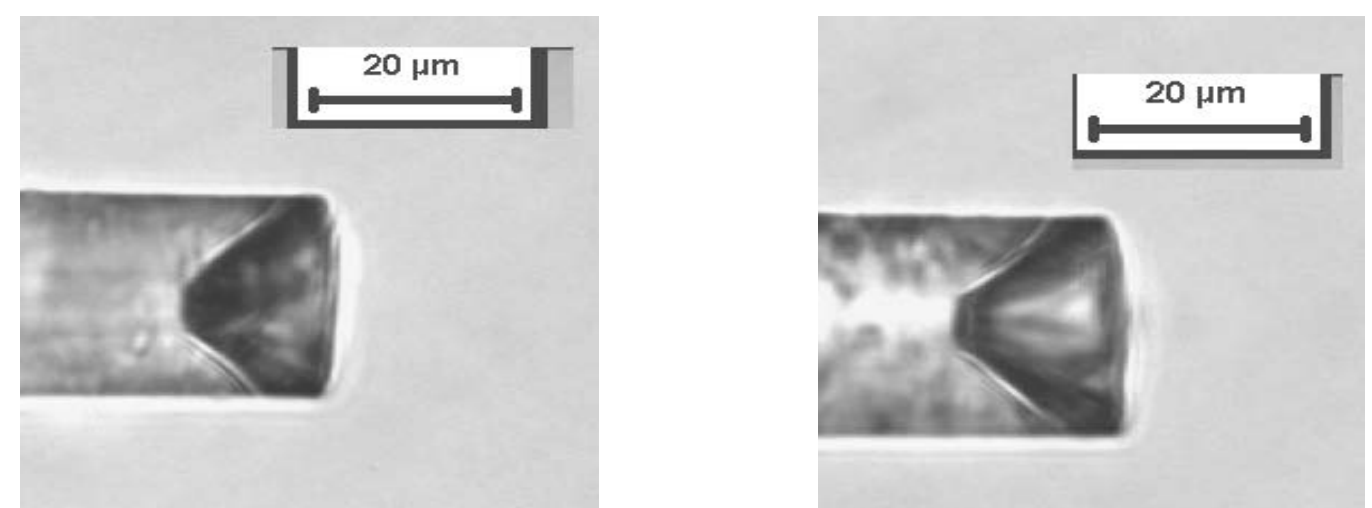

Figure 4. Optical micrographs of SM800 fibre etched in agitated HF acid.

\subsection{FP Construction and Mechanical Test Results}

Cavities produced through etching of cleaved optical fibre end-faces were tested for their ability to produce Fabry-Pérot fringes using the CCD interrogation scheme descibred in section 3.1.1. The spectra in Figure 5 show etched fibres butted to a standard cleaved fibre end; the etched fibre ends were kept parallel by the "v" groves 
of the fusion splicer. The fibres were then moved away from the cleaved fibre resulting in a change in the cavity length recorded by the interrogation scheme.

Figure 5 shows fringe patterns correlating to cavity gaps of $41.8 \mu \mathrm{m}, 52.6 \mu \mathrm{m}$ and $110.6 \mu \mathrm{m}$.

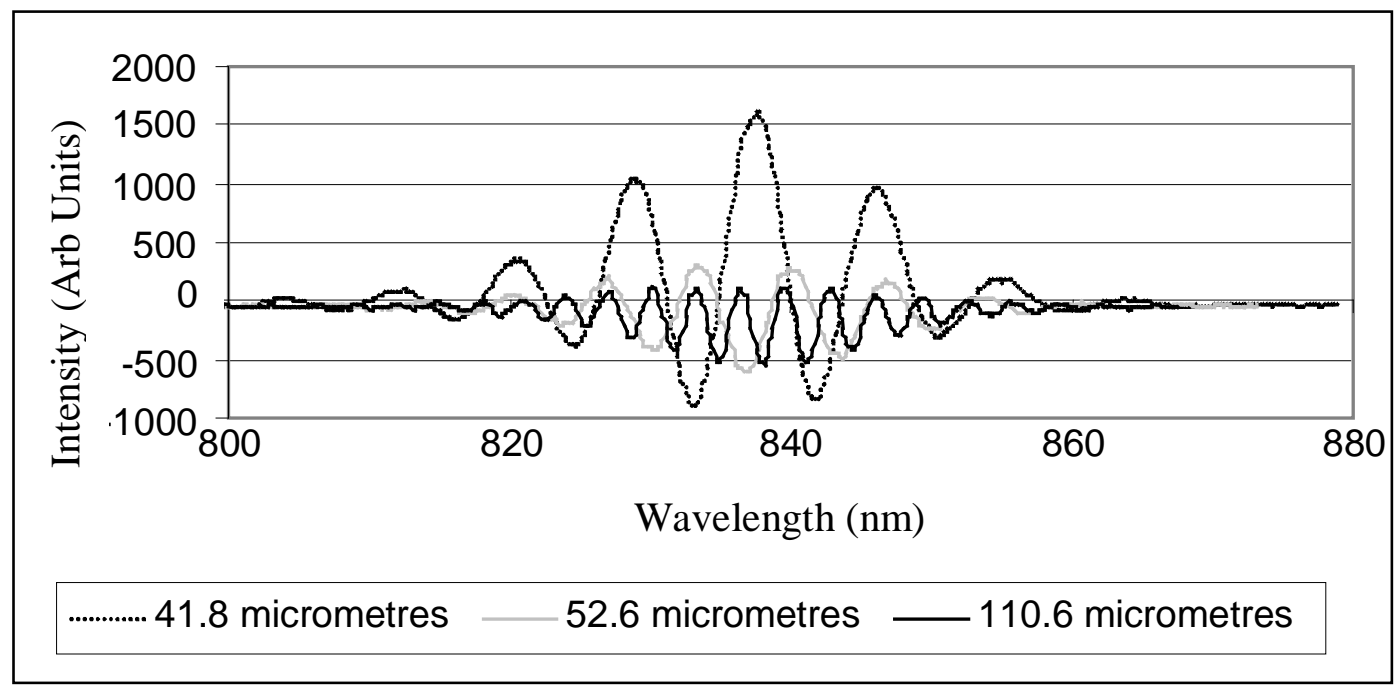

Figure 5. Spectra of single etched SM800 fibres and a cleaved SM800 fibre end.

These etched optical fibres are clearly suitable for Fabry-Pérot construction as they demonstrate Fabry-Pérot fringes.

\subsubsection{Fusion Splicing of Etched Optical Fibres}

The next stage of sensor development for the etched fibre-ends was to produce a fixed cavity. Two etched fibres of the same diameter were aligned and fused together to form a cavity between the two fibres. The spectra shown in Figure 6 show two etched fibres butted together and subsequently spliced together. 


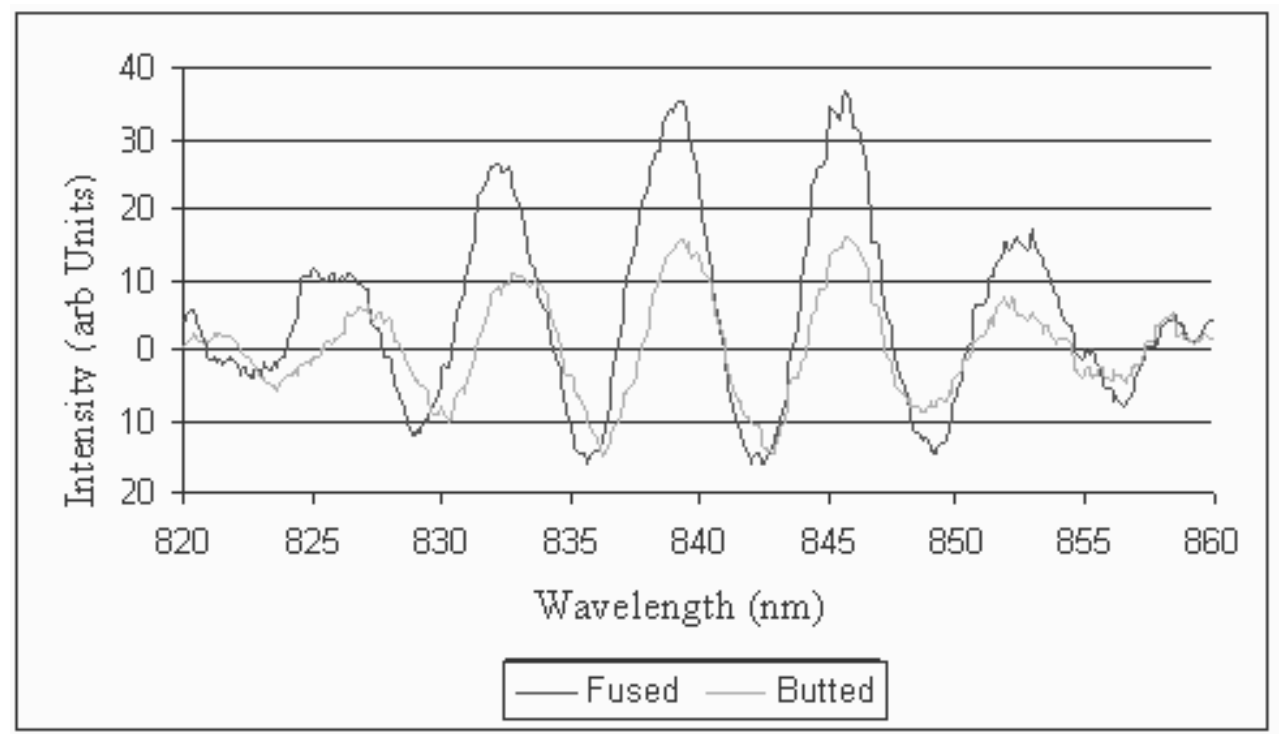

Figure 6. Fabry-Pérot fringes of SM800 etched optical fibre.

A change in the cavity length and a small increase in the intensity of the fringes is evident. The change in cavity length will be due to melting of the contact points of each fibre; cavity shrinkage would therefore be expected. Measurement of the cavity length shows a reduction from $57.3 \mu \mathrm{m}$ to $53.8 \mu \mathrm{m}$ is apparent. The increase in intensity of the fringes could be due to two factors both related to the splicing mechanism. Melting could remove any bending of the fibres when the fibres are butted together and produce cavities parallel with respect to each other ${ }^{27}$. Secondly, the heating of the fibre ends may provide an opportunity for surface asperities to relax and therefore smooth the surface, providing a better reflective surface. Figure 7a, displays a complete sensor with the FP cavity clearly highlighted and b, shows the resultant fringes from the etched cavity. 




(a)

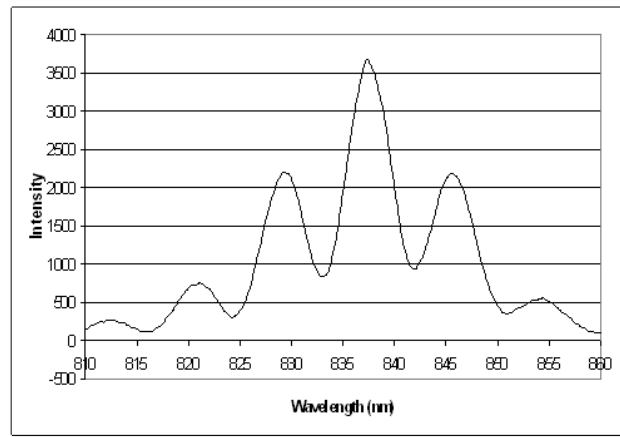

(b)

Figure 7. (a) Etched in-line fibre Fabry-Pérot sensor. Here two SM800 fibres that etched for 30 minutes were fusion spliced. (b) Resultant Fabry-Pérot interference fringes that corresponds to a cavity of approximately $41 \mu \mathrm{m}$.

\subsection{Tensile Testing of Etched Fibre Sensors.}

Strain testing of the fusion spliced etched cavities was performed on a Hounsfield and Zwick Tensometers. The sensors were attached to stainless steel coupons and strain was applied. Initial testing of the fusion spliced etched cavities was performed on Hounsfield tensometer. The following two graphs show an etched sensor loaded, up to $2.2 \mathrm{kN}$.

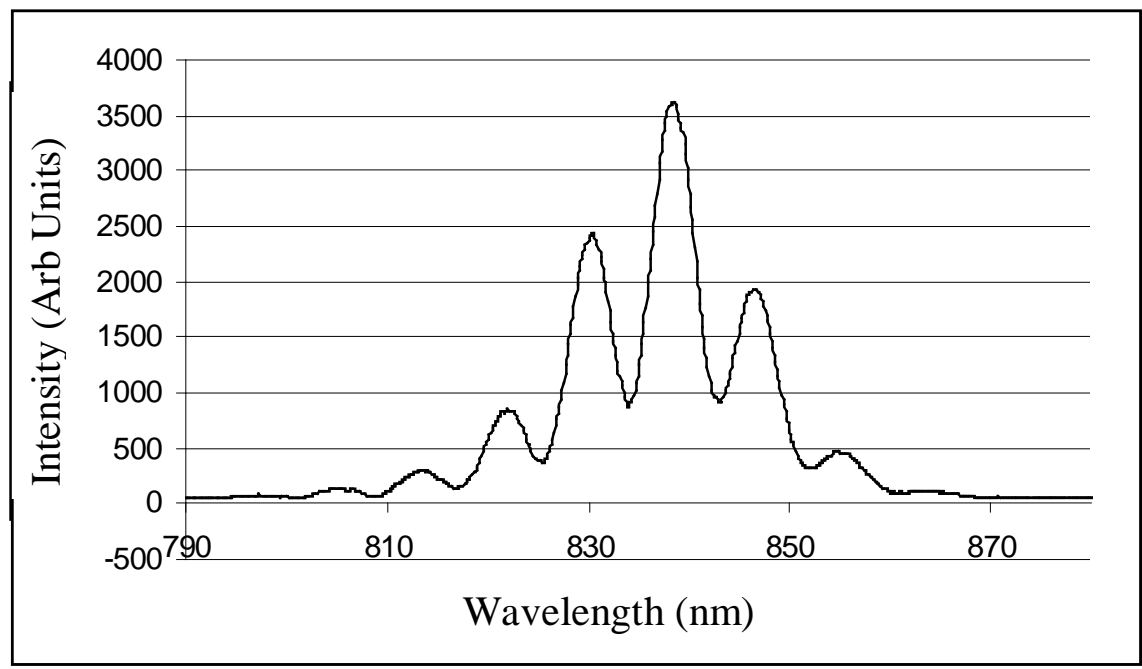

Figure 8 Spectrum of cavity deployed on Hounsfield Tensometer.

Figure 9 shows the extension of a $42 \mu \mathrm{m}$ cavity when loaded from 0 to $2.2 \mathrm{kN}$ in 0.5 $\mathrm{kN}$ steps (Figure 9, 300 to 550 seconds). Direct loading up to $2.2 \mathrm{kN}$ was performed between 550 and 600 seconds. 


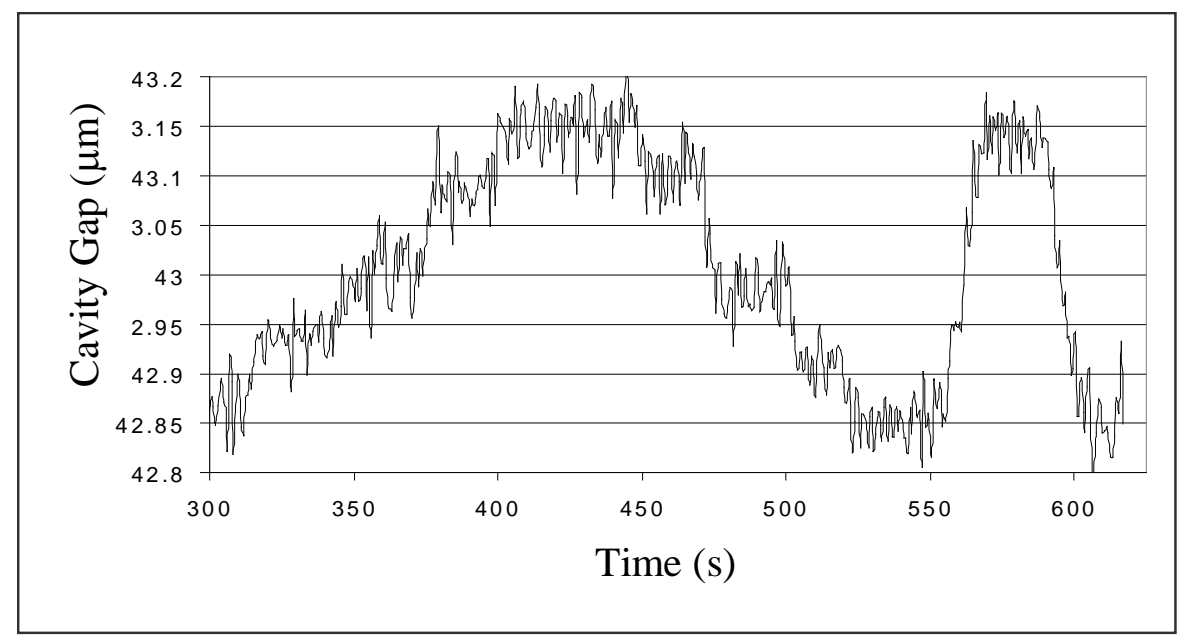

Figure 9. Cavity gap increase for the sensor in Figure 8.

Clear steps can be seen when the coupon was stepped up to $2.2 \mathrm{kN}$. It is therefore clear that the strain is being transferred from the coupon to the fibre and has translated into an increase of the cavity length.

Tensile testing of similar cavities was performed with larger strain increases in order to produce larger changes in the cavity extension. Sensors with cavity gaps of $18 \mu \mathrm{m}$ (two 10 minute etched fibres) and around $50 \mu \mathrm{m}$ were used. Figure 10 shows the response of an $18 \mu \mathrm{m}$ etched cavity sensor.

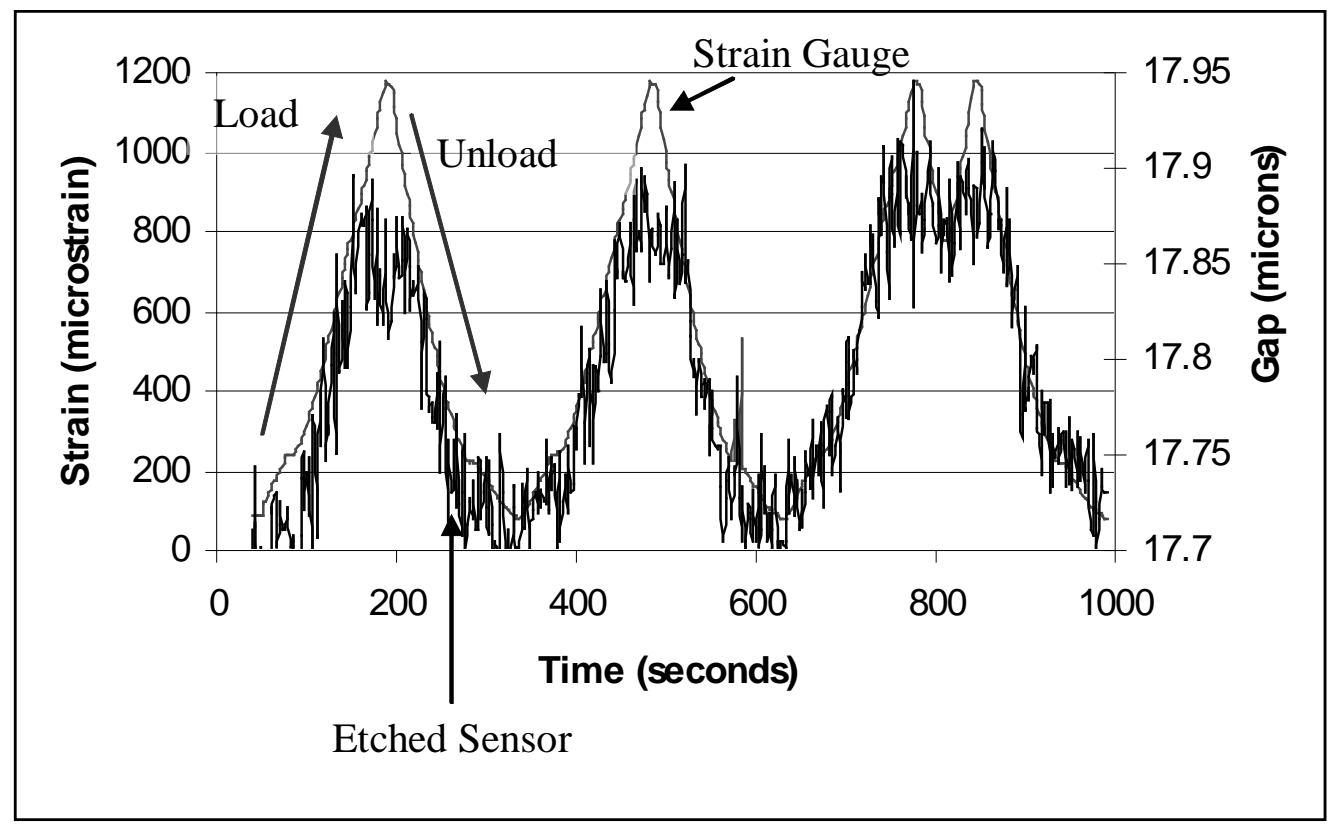

Figure 10. Response of an $18 \mu \mathrm{m}$ etched cavity to strain on a stainless steel bar. 
The sensor shows a direct response to strain. However, on the third cycle the response to unloading to $2.5 \mathrm{kN}$ is less obvious than the sensor presented in Figure 11. The sensor in Figure 11 differs only in the size of the etched cavity; $54 \mu \mathrm{m}$ compared to $18 \mu \mathrm{m}$.

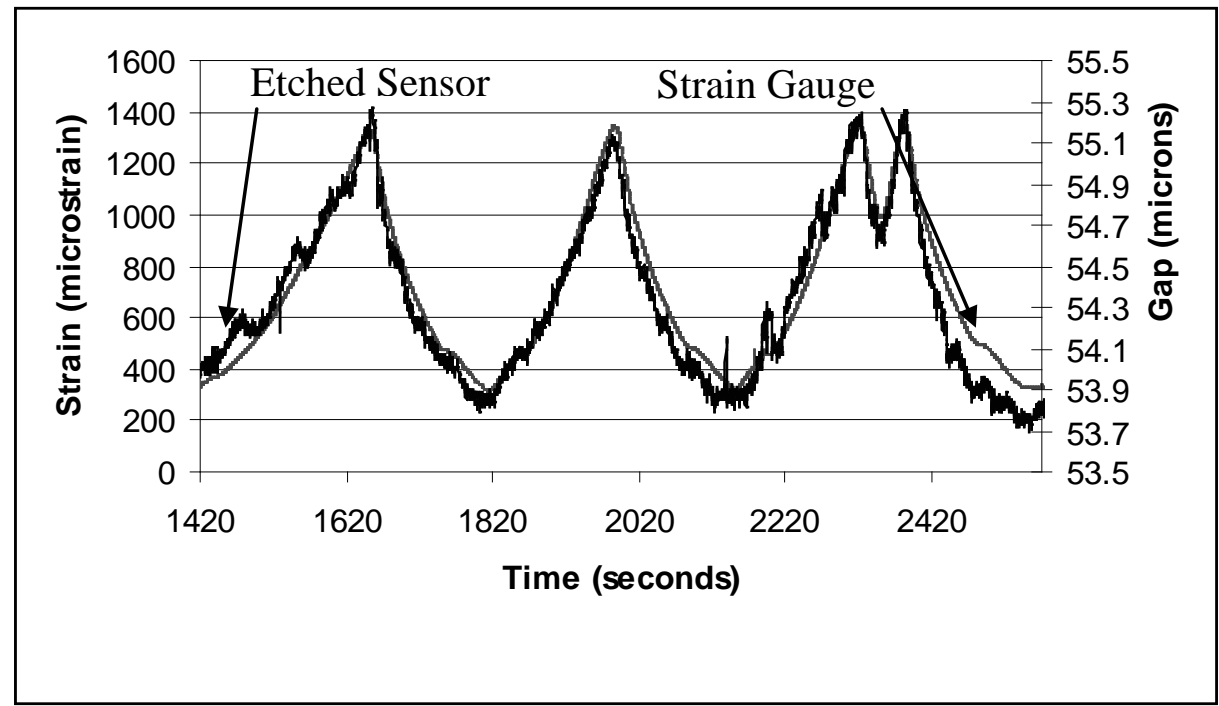

Figure 11. Response of a $54 \mu \mathrm{m}$ etched cavity to strain on a stainless steel bar.

In Figure 10 and Figure 11 the response of two fibre sensors produced with the cavity etching technique is presented. The $54 \mu \mathrm{m}$ sensor clearly extended more than the 18 $\mu \mathrm{m}$ cavity $(1.6 \mu \mathrm{m}$ compared with $0.2 \mu \mathrm{m})$. The loading conditions for the two sensors were identical and both sensors survived the test still attached to the coupon, indicating that the differences in sensor construction changed the sensing properties. The sensor in Figure 11 also shows an interesting feature on the etched fibre trace, as a step function is seen in the early part of the test (1420 to 1620 seconds). This stepping function is not part of the loading cycle as no such effect was seen by the strain gauge trace. This effect coincided with fringes being observed to appear and disappear through a threshold value set on the interrogation software (not recorded by the interrogation unit); the cavity gap calculation performed by the interrogation software relies on a generic peak finding algorithm that can be affected by the number of peaks visible above the threshold. These fluctuations in the sensor spectrum resulted in changes to the recorded gap length. 
These sensors are analogous to In-Line Fibre Etalon (ILFE) ${ }^{14}$ based sensors, i.e. the gauge length for these types of sensor is the cavity gap. Therefore increasing the gauge length of these sensors will make them more sensitive to strain. In terms of temperature stability, again the sensors are analogous to ILFE devices. Fused silica has a thermal expansion coefficient of around $0.55 \times 10^{-6}{ }^{\circ} \mathrm{C}^{-1}$, thus a 100 temperature rise for a $50 \mu \mathrm{m}$ cavity would result in an extension of only $2.75 \mathrm{~nm}$. With the demodulation equipment used here, temperature effects were not recordable.

With all the sensors shown, although they responded linearly with the applied strain on the coupon, the readings are only for extension of the etched cavity. The sensors would therefore need calibration before reliable strain readings can be taken. Using the sensor shown in Figure 11, an extension of approximately $1.6 \mu \mathrm{m}$ was realised for around $1000 \mu \varepsilon$ on the coupon resulting in $625 \mu \varepsilon$ per $1 \mu \mathrm{m}$ of movement in the cavity for this sensor. According to Liu et al. ${ }^{23}$, the CCD interrogation scheme used can monitor cavity changes of $0.6 \mu \mathrm{m}$, giving the sensor a strain resolution of $375 \mu \varepsilon$. It should be noted however that the data presented in Figure 10 is monitoring only a $0.2 \mu \mathrm{m}$ change in the cavity. Using this data could mean that the system is able to monitor strain changes of $125 \mu \varepsilon$. By improving the interrogation scheme to monitor smaller changes in cavity length or by increasing the length of the cavity, the strain resolution of the etched FP sensors could be increased.

\section{Conclusions}

The etching of cleaved optical fibre-end-faces has been carried out. This method has been shown to produce cavities on cleaved end-faces with a suitable etchant (in this case HF acid) that follow the dopant profile of the fibre. By increasing etching time, cavities with a depth of up to $30 \mu \mathrm{m}$ have been produced in a single fibre. Standard singlemode (SM800) fibre with $\mathrm{GeO}_{2}$ doped core regions produced a cavity suitable for producing Fabry-Pérot fringes.

The cavities are produced because of differential etch rates between the cladding and the core region. This difference resulted in an etch rate of $1 \mu \mathrm{m} \mathrm{min}{ }^{-1}$ greater for the core. Agitation increased rates greatly, producing fibres with a cladding diameter of only $25-30 \mu \mathrm{m}$; this concurs with studies by previous authors. This increase in etch 
rate however did not result in deeper cavities as the effects impinged on both cladding and core regions.

Singlemode fibres etched using HF acid were spliced together to form Fabry-Pérot cavities within a fibre structure. The consequent devices were used to monitor the application of strain on a stainless steel coupon. Strain was translated successfully to the sensing etched cavity, with a linear response to applied strain. This etching technique has proved successful for Fabry-Pérot étalon production and use as sensors.

The chemical etching technique reduces the manufacturing steps for an EFP to just three steps: strip and cleaving of the fibre, etching and splicing. Components are reduced to just optical fibre. With further refinement in may be possible to produce deeper cavities (by masking) and faster through agitation. This could lead to this technique becoming a very real alternative to traditional manufacturing techniques for EFP strain sensors.

\section{References}

1 DOYLE C., MARTIN A., LIU T, WU M., HAYES S., CROSBY P.A., POWELL G.R., BROOKS D. and FERNANDO G.F. "In-situ process and condition monitoring of advanced fibre-reinforced composite materials using optical fibre sensors” Smart Materials And Structures, 1998, 7, pp 145-158.

2 GRATTAN K.T.V. And MEGGIT B.T. “Optical fiber sensor technology: Volume 3”, Optoelectronics Imaging and Sensing, Kluwer Academic Publishers, 1999

3 SINGH M., TUCK C.J. and FERNANDO G.F. “Multiplexed optical fibre FabryPérot sensors for strain metrology” Smart Materials and Structures, 1999, 8, pp. 549553.

4 KERSEY A.D., JACKSON D.A. and CORKE M. "A simple fibre Fabry-Pérot sensor” Optics Communications, 1983, 45, pp. 71-74.

5 HENDERSON P.J., RAO Y.J., JACKSON D.A., ZHANG L. and BENNION I. "Simultaneous multi-parameter monitoring using a serial fibre Fabry-Pérot array with low coherence and wavelength domain detection" Measurement Science and Technology, 1998, 9, pp.1837-1898 
6 BAO X., DHILWAYO J., HERON N. WEBB D.J. and JACKSON D.A.

"Experimental and theoretical studies on a distributed temperature sensor - based on Brillouin scattering” Journal of Lightwave Technology, 1995, 13, pp. 1340-1348 7 DE SOUZA K., CULVERHOUSE D.O. and NEWSON T.P., "Dual-operation Qswitched erbium-doped fibre laser for distributed fibre sensing” Electronics Letters, 1997, 33, pp. 2040-2042

8 FARAHANI M.A. AND GOGOLLA T. "Spontaneous Raman Scattering in Optical Fibers with Modulated Probe Light for Distributed Temperature Raman Remote Sensing” Journal of Lightwave Technology, 1999, 17, pp. 1379-1391

9 JAMES S.W., TATAM, R.P., TWIN A., MORGAN M. AND NOONAN P. "Strain Response of Fibre Bragg grating Sensors at Cryogenic Temperatures” Measurement Science and Technology, 2002, 13, pp. 1535 - 1539

10 Presentation: BREIDNE M. "Bragg gratings and the patent situation”, Fibre Optic Sensors - European Network, 14 - 15th October 1999, Rome.

11 HARAN F.M., REW J.K. and FOOTE P.D. “A strain isolated fibre Bragg grating sensor for temperature compensation of fibre Bragg grating strain sensors” Measurement Science and Technology, 1998, 9, pp. 1163-1166.

12 BELLEVILLE C., and DUPLAIN G. "White-light interferometric multimode fiber-optic strain sensor”, Optics Letters, 1993, 18, pp 78-80.

13 LEE C.E., GIBLER W.N., ATKINS R.A. and TAYLOR H.F. "In-line fiber Fabry-Pérot interferometer with high reflectance internal mirrors” Journal of Lightwave Technology, 1992, 10, pp 1376-1379.

14 SIRKIS J. BERKOFF T.A. JONES R.T. SINGH H. KERSEY A.D. FRIEBELE E.J. and PUTNAM M.A. "In-line fiber étalon (ILFE) fiber-optic strain sensors” Journal of Lightwave Technology, 1995, 13, pp 1256-1263

15 RAO Y.J., COOPER M.R., JACKSON D.A., PANNELL C.N., and REEKIE L. “Absolute strain measurement using an in fiber-bragg grating based Fabry-Pérot sensor” Electronics Letters, 2000, 36, pp. 708-709

16 LEE C.E., ALCOZ J.J., YEH Y. GIBLER W.N. ATKINS R.A. and TAYLER H.F. “Optical fiber Fabry-Pérot sensors for smart structures” ADPA/AIAA/ASME/SPIE Conference on active materials and adaptive structures, 1992, pp.657-660.

17. MILLER C, METTLER S.C. and WHITE I.A., Optical Fiber Splices and Connectors: Theory and Methods, 1986, Marcell Dekker Inc. 
18 ORTHNOS A AND KALI K, Fibre Bragg Gratings,Fundamentals and Applications in Telecommunications and Sensing, 1999 (London: Artech House Publishers)

19 MONK D.J., SOANE D.S. and HOWE R.T. “A review of the chemical reaction mechanism and kinetics for hydrofluoric acid etching of silicon sioxide for surface micromachining applications” Thin Solid Films, 1993, 232, pp. 1-12.

20 MURPHY V., MACCRAITH B.D., BUTLER T., MCDONAGH C. and LAWLESS B. "Quasi-distributed fibre-optic chemical sensing using telecom optical fibre” Electronics Letters, 1997, 33, pp.618-619.

21 ABEYSINGHE D.C., DASGUPTA S. BOYD J.T. and JACKSON H.E. “A novel MEMS pressure sensor fabricated on an optical fibre” IEEE Photonics Technology Letters, 2001, 13, pp. 993-995.

22 Zhu YZ; Pickrell, G; Wang XW; Xu, JC; Yu , B; Han, M; Cooper, K; Wang, AB; Ringshia, A and Ng, W; "Miniature Fibre Optic Pressure Sensor for Turbine Engines” Sensors for Harsh Environments 11-18, Proceedings of the Society of Photo Optical Instrumenttion Engineers, 5590, October 2004, Philadelphia 23 LIU T., WU M., RAO Y., JACKSON D.A. and FERNANDO G.F. “A multiplexed optical fibre based extrinsic Fabry-Pérot sensor system for in-situ strain monitoring in composites” Smart Materials and Structures, 1998, 7, pp. 550-556.

24 TSO S.T. and PASK J.A. "Reaction of glasses with hydrofluoric acid solution" Journal of the American Ceramic Society, 1982, 65, pp. 360-362.

25 GREENWOOD N. N. and EARNSHAW A. "Chemistry of the Elements 2nd Edition”, Butterworth Heinemann, 2001, p 382

26 WEAST. "Handbook of Chemistry and Physics” CRC Press, 1981-1982, 62nd Edition.

27 ARYA V., de VRIES M.J., WANG A. and CLAUS R.O. “Analysis of the effect of imperfect fiber endfaces on the performance of extrinsic Fabry-Pérot interferometric optical fiber sensors” Optical Engineering, 1996, 35, pp. 2262-2265. 